\title{
Teaching Resilience to Aspiring Educational Leaders
}

\author{
Dr. Lin Carver \\ Saint Leo University, \\ PO Box 6665, Saint Leo, FL 33574 \\ Dr. Jodi Lamb \\ Saint Leo University, \\ PO Box 6665, Saint Leo, FL 33574
}

\begin{abstract}
Resiliency in practicing and aspiring educational leaders is an attribute that contributes to extended effectiveness and longevity. This pilot study examines research about resiliency and compares the identified methods to those methods employed by university educational leadership programs to support and enhance resiliency development in their candidates. This pilot study examines survey Likert and open-ended responses from thirteen educational leadership programs throughout the United States with a combined total enrollment of over a thousand students. The strategies are divided into four categories based upon the ways that students interact with the resiliency content: concept building, vicarious, problem solving, or relationships. The literature indicated interpersonal and problem solving were the most influential activities recommended for teaching resilience; however, the most frequent types of activities identified by educational leadership programs were vicarious experiences and relationships. The preliminary findings indicate the importance of expanding problem solving experiences. In addition, a more thorough investigation of the role that interpersonal relationships play in developing resilience would be an important area for future study.
\end{abstract}

Key Words: educational leadership, aspiring leaders, resilience

\section{INTRODUCTION}

Being a school or district leader is a tough and demanding position. Current and aspiring leaders are faced with a long list of pressures due to the present political climate and its heavy emphasis on increasing and evaluating student achievement through standardized testing. Leading a school where the faculty, staff and students work really hard, but fail to make consistent gains can create experiences that are exhausting and often deflating. Taking over a struggling school where the instruction lacks rigor, the students are not engaged, and the faculty are apathetic could appear to be as daunting a task as climbing Mount Everest to some leaders and exciting and motivating to others. Resilience might be the factor that makes the difference.

\section{LITERATURE REVIEW}

This study takes a closer look at resilience to ask how resilience can be taught or enhanced in educational leadership programs. Resilience has been described in a variety of ways. Patterson and Reed (16) defined resilience as "using energy productively within a school environment to achieve goals in the face of adverse conditions" (p. 89). Sommer, Howell, and Hadley (20) determined that resilience through "transformational leadership was associated with greater levels of positive affect and lower levels of negative affect which, in turn, predicted higher resilience among team members" (p. 172). Pierre-Farid (17) found that even 
during the most trying of days, resilient principals felt a sense of hope and optimism and that those principals would enter school the next day with a new set of strategies to use to maintain focus. According to Driver (3) "...resilient leaders anticipate that disruptive events will occur and that a tolerance for ambiguity is necessary. Resilient women leaders believe that good things can happen in spite of challenging circumstances..." (p. 44).

\section{Characteristics of Resilience}

Resilience is a term frequently used, but as is obvious by Driver's work that is cited in the previous section, it is characterized in a variety of ways. Three studies in particular attempted to identify the specific characteristics of resiliency. Patterson, Patterson, and Collins (15) identified seven strengths of resilient school leaders: 1) willingness to take charge based on values, 2) personal and professional support systems that focus on what matters, 3) flexibility in goal achievement, 4) staying positive about growth in the face of adversity, 5) remaining focused on what matters, 6) maintaining high expectations for all, and 7) creating a climate of shared responsibility.

Patterson and Reed (16) consolidated this list to the five most important characteristics of successful resilient leaders: 1) personal values driven, not event driven; 2) caring and supportive base; 3 ) examination of disruptions and expectations; 4) positive about future growth and improvement; and 5) courage of convictions in the face of opposition.

Dole (2), through interviewing 24 resilient female educational administrators, identified three broad characteristics (themes) of resilience. The first theme she identified was a strong sense of perseverance and faith, which is similar to Patterson and Reed's (16) first characteristic of being values driven. The second theme Dole identified was positive support relationships which aligns with Patterson and Reeds second characteristic of supportive relationships. The final theme Dole identified combines Patterson and Reed's last three characteristic into the ability to reframe barriers into successes. (See Table 1)

Table 1

\section{Characteristics / themes of Resilience as Identified by Various Researchers}

\begin{tabular}{lll}
\hline $\begin{array}{l}\text { Patterson, et al. } \\
(15)\end{array}$ & $\begin{array}{l}\text { Patterson \& Reed } \\
(16)\end{array}$ & \multicolumn{1}{c}{$\begin{array}{c}\text { Dole } \\
(2)\end{array}$} \\
\hline Personal Values & Personal Values & Perseverance \& Faith \\
Caring Support Base & Caring Support Base & Positive Support System \\
Flexibility in Problem Solving & Evaluating Problems & Ability to Reframe Barriers \\
Staying Positive & Staying Positive & \\
Focused & Courage in Face of Opposition & \\
High Expectations & & \\
Shared Responsibility & & \\
\hline
\end{tabular}

\section{Academic Resilience}

Resilience is viewed as important in relation to all stakeholders of the academic community: students, teachers, and administrators. Research findings indicate that resilience is not necessarily a fixed attribute, but can change depending on the specific time and circumstances; however, it is characterized as a combination of traits that enable individuals, whether they are students, teachers, or administrators, to withstand and/or recover quickly from difficult conditions they experience (5). Academic resilience as defined by Morales and Trotman (11) is "the process and results that are part of the life story of an individual who has been academically successful, despite obstacles that prevent the majority of others with the same 
background from succeeding" (p. 8). In her study, Driver (2) determined protective factors that consistently appeared in resilient leaders: ability to reject rejection, personal hardiness, spirituality, and a strong sense of cultural identity. She states that, "Resilience is more than the ability to bounce back. It means withstanding pressure and showing flexibility and adaptability" (p. 152).

Patterson, Collins and Abbot (14) determined that teacher leader resilience provides the foundation for successful school improvement and reform efforts. Through a descriptive study, they identified strategies that teacher leaders use to remain resilient. They are: 1) using personal core values to guide decision making, 2) placing priority on obtaining meaningful professional development, 3) mentoring others, 4) being active problem solvers, 5) remaining focused on student learning, 6) helping children to be successful, 7) maintaining and seeking friendships with supportive colleagues, 8) having a willingness to try new instructional approaches to better meet student needs, and 9) knowing when to get involved and when to step away.

\section{Impact of Resilience}

Maulding, Peters, Roberts, Leonard, and Sparkman (10) determined that emotional intelligence and an individual's resilience, rather than school characteristics, directly impacted leadership success. The researchers determined that resilience has a potential impact on the school's culture which, in turn, has an indirect impact on student achievement. They found a significant positive relation between increased emotional intelligence and resilience and increased leadership capacity. According to Hattie (6), the positive influence of a leader, as evidenced by the above relationship, has been shown to impact teacher efficacy and school culture positively which, in turn, enhances student achievement.

Because of the increase in the number of women in educational leadership positions the researchers felt it was important to consider the role that gender played in developing resilience in educational leadership. Christman and McClellan (1) conducted a study that looked at resilient women administrators in educational leadership programs and examined the possibility that their resiliency was tied to a feminine style of leadership. Their findings indicated that resilient women leaders tend to embrace a multidimensional gendered leadership model instead of embracing a predominately feminine leadership model.

Offutt (13) examined the relationship between resilience and elementary school principals' leadership practices. In her study recommendations, she suggests that "educational leadership program in colleges and universities could consider the inclusion of leadership training strongly grounded in resilience practices" (p. 102).

\section{Process of Teaching Resilience}

Reyes, Andrusyszyn, Iwasiw, Forchuk, and Babenko-Mould (18) examined students' understanding and application of resilience developed through a process of steps. Students began by learning about the challenges inherent within the setting, being willing to try a variety of solution, and finally acknowledging and discussing the challenges they were experiencing with peers and other support systems. Similarly, Lopez, Yobas, Chow, and Shorey (8) found that adapting and learning the culture was a gradual process for students as they started off by facing challenges head-on and learned and adapted to the culture after accumulating experiences throughout their academic career. Therefore, individuals can learn to be resilient by being exposed to challenges and possible solutions in a variety of ways. These could involve reading about solutions, hearing about other's experiences, developing potential solutions, or talking with others who provide a support system $(8,18)$. 
Facilitating the development of many of these same traits have been identified as important in the development of leader resiliency. Hoffman (7) focused on building resilience in educational leaders already employed in the school system. For those leaders already employed, he found that "resiliency among leaders can be enhanced through the creation of supportive structures and norms within school districts" (p. 38). Hoffman (7) determined that team building and effective coaching provided the supportive structures needed to enhance leader resiliency. Incorporating these practices helped to create a culture that energized and rewarded school leaders.

If leadership candidates become better prepared to meet the challenges presented in school leadership, exposure to the challenges in a variety of ways might help to prepare future leaders to effectively lead the learning environment. Mangham, McGrath, Reid, and Stewart (9) indicated that resilience is a capacity that can be enhanced over time. Resilience is a fluid process so it is critical to determine how resilience can be instilled in aspiring administrators.

Schechter (19) identified problem-based learning (PBL) as a beneficial strategy for preparing aspiring school leaders. The PBL process contributed to candidates' analytic and strategic thinking skills. Consequently, PBL through case studies and research has resulted in increasing application in principal preparatory programs. In addition, he stressed the effectiveness of the development of interpersonal relationships to enhance leaders' resilience thus stressing the importance of creating these relationships for aspiring leaders. Based on Hoffman's (7) research on developing resilience in employed educational leaders, he identified the importance of expanding a leader's understanding and resilience through book studies, joint problem solving, and interpersonal relationships.

\section{RESEARCH QUESTIONS}

The researchers of this study were interested in determining answers to the following questions:

1) How does the type of institution or its location impact instruction in resiliency within the educational leadership program?

2) What methods do educational leadership programs in higher education institutions use to support or enhance the development of resilience in their graduate students who are in educational leadership programs?

3) How do methods used by universities for teaching resilience compare to methods identified by selected researchers?

\section{METHODOLOGY}

Willis (21) identified four techniques for teaching and building resilience: building competency, learning from mistakes, practicing finding solutions, and developing strong relationships. Using strategies identified in each of these four areas, the researchers developed a 13-question Likert-scale pilot survey with open-ended options to expand on their thinking. The survey began with demographic information about the institution and then asked whether resiliency was taught and assessed in the institution's educational leadership program. This section was followed by nine 4-point Likert scale (1- disagree strongly, 2- disagree, 3- agree, 4agree strongly) items with additional open-ended response boxes. Four items focused on strategies to develop competence through reading. These were followed by two items focusing on ways of learning from other's mistakes and experiences. The fourth section included three strategies for practicing finding solutions and the final section focused on mentoring. 


\section{RESULTS/FINDINGS}

The pilot survey was emailed to 75 potential completers with a return rate of $20 \%(n=15)$. Convenience sampling was used based upon universities with educational leadership programs represented at educational leadership state and national conferences. Since this was only a pilot study, descriptive statistics were used rather than attempting to generate a true random sample. Survey completers were program administrators and/or faculty members of graduate educational leadership programs throughout the United States who indicated a willingness to be involved in the project. These programs outside of the state of Florida were selected based on their willingness to participate. Representatives from all of the Florida educational leadership programs approved by the Florida Department of Education were invited to participate. Demographic data was collected regarding the size of the educational leadership program, the state in which it is located, and if the university was a public or private institution. The majority of the respondents were from universities with smaller program enrollments. Eleven of the 15 programs indicated that the number of students in their programs was between 50 - 200; while three had between 200 - 500 students, and one had between 500 and 1,000 students. Ten of the programs represented were in Florida, one was from Illinois, one from North Carolina, two from Idaho, and one was from Georgia. Responses were almost evenly divided between public and private universities. Seven were public institutions and the remaining eight were private. The emphasis on instruction in resilience in Florida was comparable to the emphasis by programs throughout the United States. These figures were comparable, ranging from 30 to 40 percent. However, institutions throughout the United States indicated a slightly higher emphasis on the assessment of resiliency in the leadership standards. Public and private institutions indicated that resiliency was assessed at a similar rate between the two types of institutions. However, there was significant difference when comparing instruction in resilience between programs in public and private institutions. Private institutions placed significantly more emphasis on providing instruction in resilience than public institutions did. In conclusion, the location of the program did not significantly impact instruction in resiliency but it did impact the assessment in resiliency. The type of program, whether public or private, appears to significantly impact whether instruction in resiliency occurred. Qualitative comments indicated that resilience "was not overtly taught" or was taught "indirectly" through discussion but was not assessed or measured.

Table 2 Instruction and Assessment of Resilience by Subgroup

\begin{tabular}{llcc}
\hline Criteria & Subgroup & Taught in Program & Assessed in Leadership Standards \\
\hline Location of Institution & United States & $30 \%$ & $100 \%$ \\
& Florida & $40 \%$ & $70 \%$ \\
Type of Institution & Public & $14 \%$ & $71 \%$ \\
& Private & $88 \%$ & $75 \%$ \\
\hline
\end{tabular}

The next section of the survey examined the methods used by programs to teach resiliency. The nine strategies for teaching resilience identified from the literature and/or the survey were divided into 4 groups based upon Willis's (21) categories: concept building, vicarious experiences, problem solving, and relationships.

Mean scores were calculated for each of the nine identified strategies and $p$ and $t$ values were calculated to determine if the item means were significantly different from the mean of the entire survey (see Table 3). The means were then compared to the overall survey mean to determine if there was a significant difference between the types of strategies used by universities. The means of the two of the items, Instructor Experiences and Analyzing national 
standards differed significantly from the overall survey mean. The data indicated that analyzing national standards was employed less frequently than other strategies by a significant difference at the $\mathrm{p}<.05$ level. Even more important, as indicated by the significance of the $\mathrm{p}$ value at <.01, was the frequency of the use of the strategy of sharing instructor experiences as compared to other methods identified in the survey.

Table 3 Strategies Used by Universities' Educational Leadership Program to Teach Resilience

\begin{tabular}{llcrl}
\hline $\begin{array}{l}\text { Type of } \\
\text { Experience }\end{array}$ & \multicolumn{1}{c}{ Strategy } & Mean & $\mathrm{t}$ & $\mathrm{p}$ \\
\hline Concept & Analyzing State Standards & 2.53 & -0.76913 & .449322 \\
& Analyzing National Standards & 2.20 & -2.72461 & $.011819^{*}$ \\
& Peer Reviewed Articles & 2.64 & -0.43403 & .334157 \\
Vicarious & Instructor Experiences & 3.40 & 2.56748 & $.00845^{* *}$ \\
& Guest Speakers & 2.80 & 0.42652 & .673533 \\
Problem Solving & Case Studies & 2.87 & 0.61329 & .545454 \\
& Applying Best Practices & 2.80 & 0.36544 & .717984 \\
Relationships & Conducting Research & 2.33 & -1.87231 & .073399 \\
& Mentoring & 3.00 & 2.02601 & .060932 \\
\hline
\end{tabular}

Note Significance- ${ }^{* *} \mathrm{p}<.01, * \mathrm{p}<.05$

The researchers of this study compared the strategies identified in the survey for teaching resilience to future administrators with those that were identified by some of the researchers included in the literature review. The comparison provided additional interesting findings. Building concepts through reading articles or books was identified over half of the university respondents (64\%) but was identified by only two of the researchers. Reading about concepts through national or state laws was not identified by any of the researchers, but the importance of incorporating state standards or laws was identified by about half of the respondents (53\%). These concept building activities were factors that were not used with as much frequency by the responding universities; however, Hoffman (7) and Willis (21) stressed their importance in developing shared vocabulary, perspectives, and goals. Comments indicated that "the construct of resiliency is not named as such, but is taught as a characteristic of successful leaders through perseverance." The category of concept building experiences was used less frequently by universities than other types of experiences.

Providing students with vicarious experiences such as discussing instructor experiences or including guest speakers, were only identified by Willis (21); however, university respondents indicated this was one of the most frequently used categories (93\%) and further supported it with guest speakers (73\%). Interestingly, comments indicated that even while discussing experiences institutions "did not refer to the construct of resiliency by name." Universities that responded to the survey viewed strategies within this category as extremely important, even though only one of the researchers discussed them.

Experiences where candidates were asked to apply theory to practice through problem solving in the manipulation of data, collection and analysis of data, or application of instructional theories was a frequently used category. This category was viewed as an important component in leaders' resilience preparation and was generally considered when constructing university educational leadership programs. Comments indicated that "many courses used case studies to apply the concepts being taught." However, this was not used as frequently as vicarious experiences. 
Interpersonal relationships through mentoring and social support were identified by Hoffman (7), Schechter (19), and Willis (21). The importance of these interpersonal relationships were unanimously identified by each of the institutions as instructional practices used in the Educational Leadership programs to teach resilience (See Table 4). Social support and modeling were not specifically disaggregated in the survey and instead were viewed a subsets of the mentoring relationship. One respondent indicated "resiliency is not explicitly discussed during mentoring, even though it is embedded in places. However, it is not sufficiently discussed."

Table 4

Comparison of Methods for Teaching Resilience as Indicated by Selected Researchers and Respondent University Educational Leadership Programs

\begin{tabular}{lllllc}
\hline $\begin{array}{l}\text { Type of } \\
\text { Experience }\end{array}$ & Strategy & $\begin{array}{l}\text { Hoffman } \\
(2004)\end{array}$ & $\begin{array}{l}\text { Schechter } \\
(2011)\end{array}$ & $\begin{array}{c}\text { Willis } \\
(2016)\end{array}$ & $\begin{array}{c}\text { Survey } \\
(2018)\end{array}$ \\
\hline Concept & $\begin{array}{l}\text { State } \\
\text { standards } \\
\text { National } \\
\text { standards } \\
\text { Articles/ } \\
\text { Book study }\end{array}$ & $\mathrm{N}$ & $\mathrm{N}$ & $\mathrm{N}$ & $53 \%$ \\
& $\begin{array}{l}\text { Instructor } \\
\text { experiences } \\
\text { Guest } \\
\text { speakers }\end{array}$ & $\mathrm{N}$ & $\mathrm{N}$ & $\mathrm{N}$ & $27 \%$ \\
\hline Vicarious & Case Studies & $\mathrm{N}$ & $\mathrm{N}$ & $\mathrm{Y}$ & $64 \%$ \\
& $\begin{array}{l}\text { Applying } \\
\text { best practice }\end{array}$ & $\mathrm{Y}$ & $\mathrm{N}$ & $\mathrm{Y}$ & $93 \%$ \\
\hline Research & $\mathrm{N}$ & $\mathrm{Y}$ & $\mathrm{Y}$ & $73 \%$ \\
\hline Problem Solving & $\begin{array}{l}\text { Mentoring } \\
\text { Social }\end{array}$ & $\mathrm{Y}$ & $\mathrm{Y}$ & $\mathrm{Y}$ & $80 \%$ \\
& Modeling & $\mathrm{Y}$ & $\mathrm{Y}$ & $\mathrm{N}$ & $80 \%$ \\
\hline Relationships & & $\mathrm{Y}$ & $\mathrm{Y}$ & $40 \%$ \\
\hline & & & $\mathrm{Y}$ & $100 \%$ \\
& & & & $\mathrm{~N}$ \\
\hline
\end{tabular}

Note: Identified $=\mathrm{Y} \quad$ Not identified $=\mathrm{N}$

\section{DISCUSSION}

It is clear that most of graduate educational leadership programs that responded to the survey addressed resiliency in some way. In fact, even though it was not addressed the same way by each institution, respondents indicated that resilience was addressed in multiple ways within each of the educational leadership programs. The four most frequent methods were through mentoring, the sharing of instructor experiences, guest speakers, and case studies. Further examination of the data by type of experience provided interesting information to be considered when constructing educational leadership programs. Candidates' application of theory to data or vicarious experiences were included more frequently in graduate programs as compared to concept building through the reading of law, articles, or books. This would indicate the need for a further examination of the instructional practices being used to build an understanding of the concept of resiliency within educational leadership programs.

It is interesting to note that Professional Standards for Educational Leaders of 2015 (12) and the Florida Principal Leadership Standards (4) both specifically address the importance of resiliency. In fact, practicing administrators in Florida are evaluated based upon two indicators that address resiliency. Domain 4, Standard 10, indicator B reads: "Demonstrates 
resiliency by staying focused on the school vision and reacting constructively to the barriers to success." Domain 4 Indicator E indicates that the administrator demonstrates willingness to admit error and learn from it (4). The evidence from the literature would seem to indicate that reading about the law or research that has been completed on resilience was not viewed as effective as other methods for building resilience.

The researchers and the universities all viewed mentoring to be the most effective method for teaching resilience. Because social support and modeling were viewed as components of mentoring, examination of mentoring programs within educational leadership programs should be investigated more specifically to determine the types of experiences to include within the mentoring programs. Since this was a pilot study, it provides the direction for future study in the area of resilience.

\section{FUTURE STUDIES}

As with any study, this study seems to raise more questions than it answers. In future studies the role of interpersonal studies should be examined more specifically. As this pilot study is expanded, it would be interesting to know how and/or whether universities have addressed the role of modeling and social support in helping their aspiring leaders to develop resilience.

Issues for future study include collecting more specific information about how case studies and best practices are used within the educational leadership programs as well as how interpersonal relationships can and are being used within educational leadership programs to help build resilience. Further investigation could examine the relationship between frequency of instruction in resilience and the length of time and candidate satisfaction in their educational leadership roles after graduation. Another area for investigation would be to ask aspiring leaders' about their perceptions of the activities that were most effective in helping them to develop resilience.

\section{LIMITATIONS}

The findings of this pilot study are limited by the size of the sample. A broader sample from a wider cross section of educational leadership programs might help to generate more applicable findings. The literature indicates that interpersonal relationships are important for building resilience; however, this study only investigated the role of mentoring in developing resilience.

It is assumed that the respondents in this study attempted to accurately represent their educational leadership programs. There is no way to determine from this study whether the gender or position of the respondents represented the opinion of the respondent or the responses accurately represented the methods used within the program. Because of this, it was difficult to determine exactly how each method was incorporated into the educational leadership program or if the views of the individual who responded reflected the emphasis and the methods incorporated throughout the entire educational leadership program at that university rather than personal opinions. It does appear that faculty of educational leadership programs in higher education are attempting to ensure that their programs address and enhance candidates' development of resiliency.

\section{References}

Christman, D. \& McClellan, R. (2008). Living on barbed wire: Resilient women administrators in educational leadership programs. Educational Administration Quarterly, 44 (1), 3-29.

Dole, S. (2014). Voices of resilience: Successful Jamaican women educators. Journal of Ethnographic \& Qualitative Research, 8(3), 144-156. 
Driver, D. (2014). Courage under fire: A qualitative analysis examining the resilience capacity of black women superintendents in urban school districts. Harvard University.

Florida Department of Education (2012). Florida principal leadership standards. Tallahassee, FL: Author.

Fraser, M., Kirby L., \& Smokowski, P. (2004). Risk and resilience in childhood. In M. Fraser (Ed.), Risk and resilience in childhood: An ecological perspective (pp. 13-66). Washington, DC: National Association of Social Workers Press.

Hattie, J (2009). Visible learning: A synthesis of over 800 meta-analyses related to achievement. New York, NY: Routledge.

Hoffman, J. (2004) Building resilient leaders. Leadership, 34, 35 - 38.

Lopez, V., Yobas, P, Chow, Y. L., \& Shorey, S. (2018). Does building resilience in undergraduate nursing students happen through clinical placements? A qualitative study. Nurse Education Today, 67, 1-5.

Mangham, C. McGrath, P., Reid, G., \& Stewart, M. (1995). Resilience: Relevance to health promotion discussion paper. Atlantic Health Promotions Research Centre, Dalhousie University. Retrieved from http://www.hcsc.gc.ca/ahc/pubs/drugs-droques/resilience-ressortpsycholoique/index e.html in Reed, D. and Patterson, J. (2007).

Maulding, W., Peters, G., Roberts, J., Leondard, E., \& Sparkman, L. (2012) Emotional intelligence and resilience as predictors of leadership in school administrators. Journal of Leadership Studies, 5(4), 20 - 29.

Morales, E., \& Trotman, F. (2010). A focus on hope: Fifty resilient students speak. University Lanham, MD: Press of America.

National Policy Board for Educational Administration (2015). Professional Standards for Educational Leaders. Reston, VA: Author

Offutt, S. (2011). An examination of the characteristic, resilience, and leadership practices in public school elementary principals. Morgantown, WV: West Virginia University.

Patterson, J. H., Collins, L., \& Abbot, G. (2004). A study of teacher resilience in urban schools, Journal of Instructional Psychology, 69(2), 118-126.

Patterson, J.L., Patterson, J.H., and Collins, L. (2002). Bouncing back: How school leaders triumph in the face of adversity. New York, NY: Eye on Education.

Patterson, J. \& Reed, D. (2007). Voices of resilience from successful female superintendents. Journal of Women in Educational Leadership, 4, 89-100.

Pierre-Farid, M. (2012). Leading urban schools takes more than leadership skills: A study about how school leaders' resilience can affect student achievement. University of Pennsylvania.

Reyes, A. T., Andrusyszyn, M. A., Iwasiw, C. Forchuk, C, \& Babenko-Mould, Y. (2015). Nursing students' understanding and enactment of resilience: A grounded theory study Journal of Advanced Nursing, 71, 2622-263.

Schechter, C. (2011). Switching cognitive gears. Journal of Educational Administration, 49(2), 143-165.

Sommer, S., Howell, J., \& Hadley, C. (2016). Keeping positive and building strength: The role of affect and team leadership in developing resilience during an organizational crisis. Group \& Organization Management. 41(2), 172 202.

Willis, J. (2016). The science of resilience: How to teach students to persevere. The Guardian. Retrieved from https://www.theguardian.com/teacher-network/2016/jan/12/science-resilience-how-to-teach-studentspersevere 